
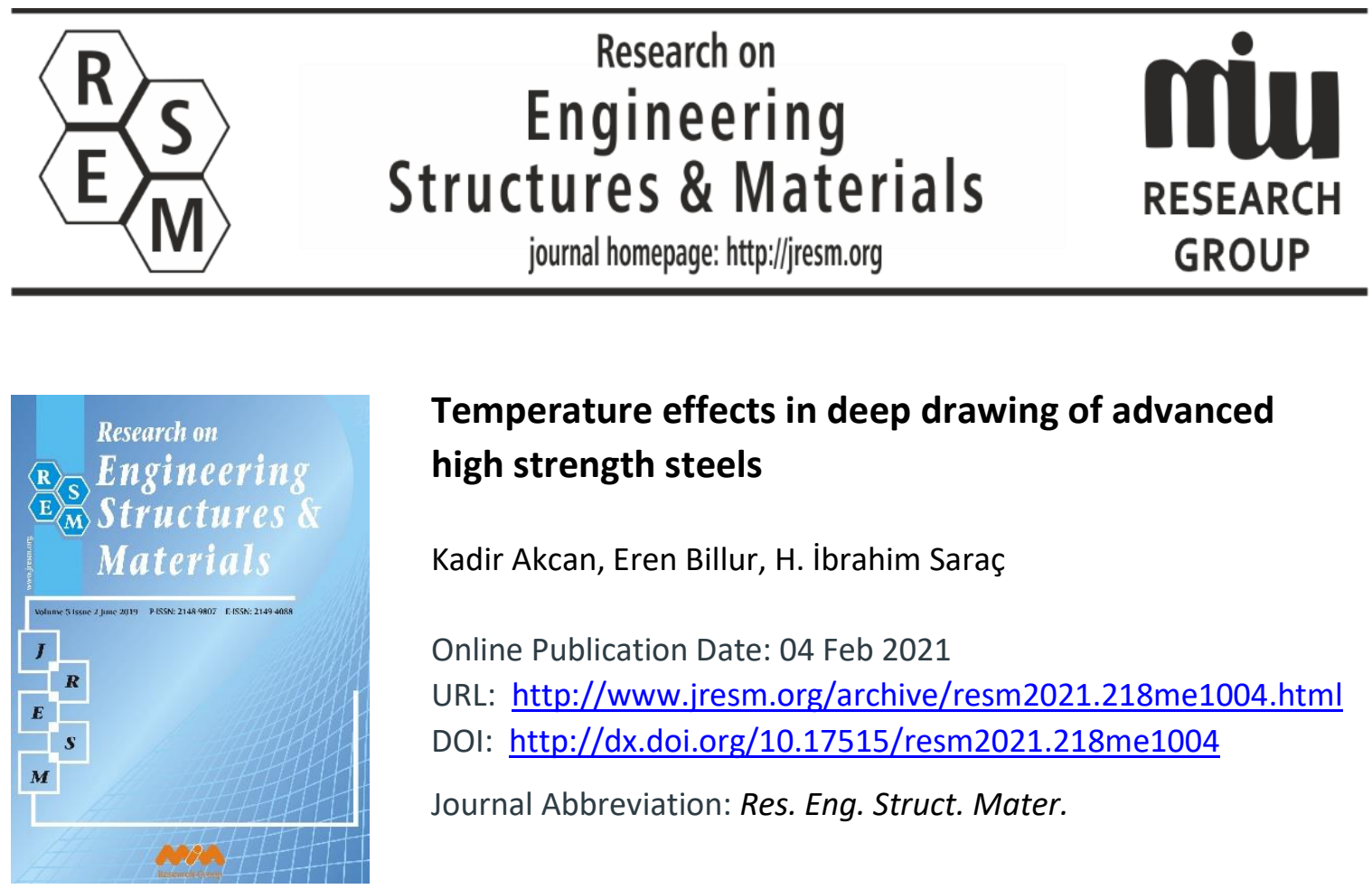

\title{
Temperature effects in deep drawing of advanced high strength steels
}

Kadir Akcan, Eren Billur, H. İbrahim Saraç

Online Publication Date: 04 Feb 2021

URL: http://www.jresm.org/archive/resm2021.218me1004.html

DOI: http://dx.doi.org/10.17515/resm2021.218me1004

Journal Abbreviation: Res. Eng. Struct. Mater.

\section{To cite this article}

Akcan K, Billur E, Saraç Hi. Temperature effects in deep drawing of advanced high strength steels. Res. Eng. Struct. Mater., 2021; 7(2): 281-295.

\section{Disclaimer}

All the opinions and statements expressed in the papers are on the responsibility of author(s) and are not to be regarded as those of the journal of Research on Engineering Structures and Materials (RESM) organization or related parties. The publishers make no warranty, explicit or implied, or make any representation with respect to the contents of any article will be complete or accurate or up to date. The accuracy of any instructions, equations, or other information should be independently verified. The publisher and related parties shall not be liable for any loss, actions, claims, proceedings, demand or costs or damages whatsoever or howsoever caused arising directly or indirectly in connection with use of the information given in the journal or related means.

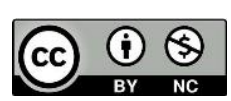

Published articles are freely available to users under the terms of Creative Commons Attribution - NonCommercial 4.0 International Public License, as currently displayed at here (the "CC BY - NC"). 


\title{
Research on Engineering Structures \& Materials
}

journal homepage: http://jresm.org

Research Article

\section{Temperature effects in deep drawing of advanced high strength steels}

\author{
Kadir Akcan ${ }^{1, a}$, Eren Billur ${ }^{* 2, b}$, H. İbrahim Saraç3,c \\ ${ }^{1}$ Ford Otosan A.Ş., Denizevler Mah. Ali Uçar Cad. No:53 41650 Gölcük, Kocaeli, TR \\ ${ }^{2}$ Department of Automotive Engineering, Atılım University, Kızılcaşar Mah., 06830, Gölbaşı, Ankara, TR \\ ${ }^{3}$ Department of Mechanical Engineering, Kocaeli University, Umuttepe Yerleşkesi, 41001, İzmit, Kocaeli, TR
}

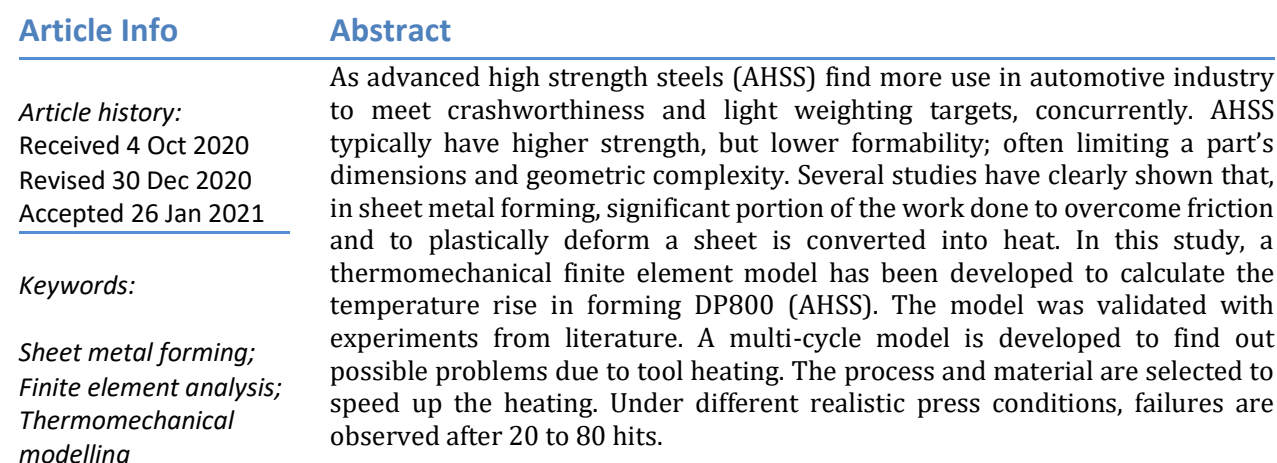

(C) 2021 MIM Research Group. All rights reserved.

\section{Introduction}

Automotive industry is pressured to reduce the emissions, while improving the crashworthiness. To achieve both targets automakers are forced to use either low density materials (such as aluminum alloys) or downgauging (reducing the thickness of the sheet) by using higher strength steels [1].

Conventional high strength steels (HSS) have been used in the automotive industry since late 1970's. In HSS, microstructure was ferritic and strengthening mechanisms were: (1) alloying with interstitials or (2) solid solution, (3) bake hardening effect (only valid for bake hardening steels in HSS), (4) carbide-forming and (5) grain refinement [2]. Conventionally, as the strength of the steel was increased, its formability would suffer. This is very well shown in the famous "banana-curve", in Figure 1.

In 1990's, automotive industry started using the multi-phase, so-called "advanced high strength steels" (AHSS). One of the first automotive applications was with the dual-phase (DP) steels (see the black dashed line in Figure 1). These steels consist of a soft ferrite matrix for formability and numerous martensitic islands for strength [3]. At similar yield strength levels, DP steels have higher elongation, compared to HSS, as seen in Figure 2.

DP steels are typically named after their tensile strength levels. For example, DP800 means a dual phase steel with approximately $800 \mathrm{MPa}$ tensile strength. A recent study by Ford of Europe showed that replacing mild steel with DP800 could save 35\% weight in crash components, as shown in Fig. 1. DP800 could be used both in axial crush regions (such as front or rear rails) and 3-point bending regions (such as rocker reinforcement and B-pillar) [4]. Since 2000's, the increase of DP steel usage in several Ford models is shown in Fig. 2.

\footnotetext{
${ }^{*}$ Corresponding author: eren.billur@atilim.edu.tr

a orcid.org/0000-0003-1454-3818; b orcid.org/0000-0001-9984-3697; c orcid.org/0000-0002-3414-3582 DOI: http://dx.doi.org/10.17515/resm2021.218me1004
} 


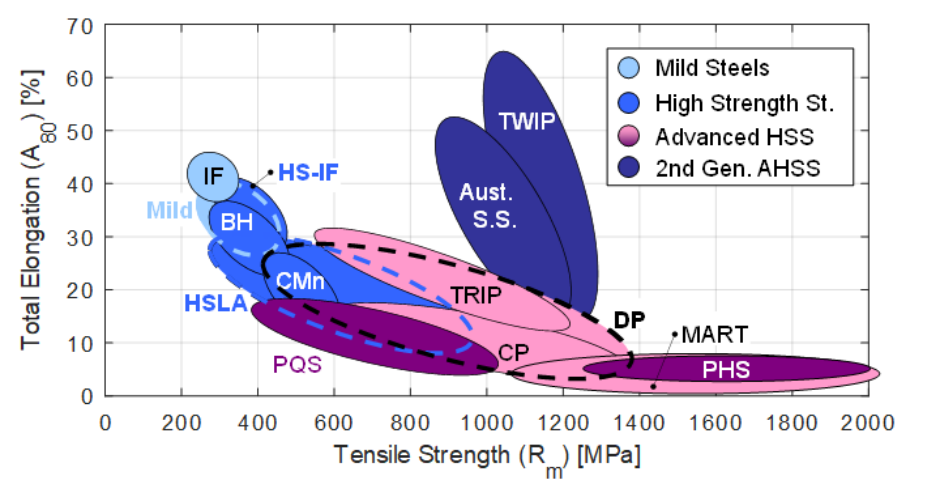

Fig. 1 Banana curve showing several automotive grades (3rd generation AHSS is omitted for better visibility)

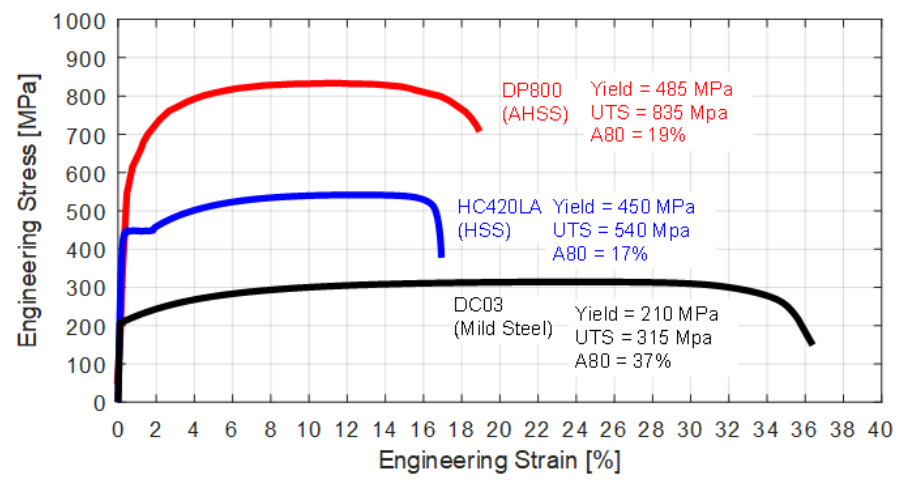

Fig. 2 Comparison of engineering stress-strain curves of DP800 with an HSS and mild steel.

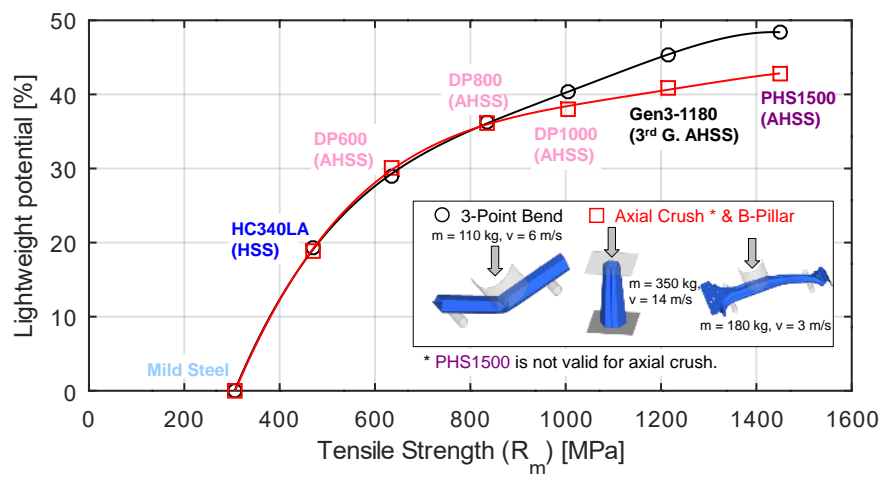

Fig. 1 Lightweight potential of several steel grades, compared to mild steel (re-created after [4]) 


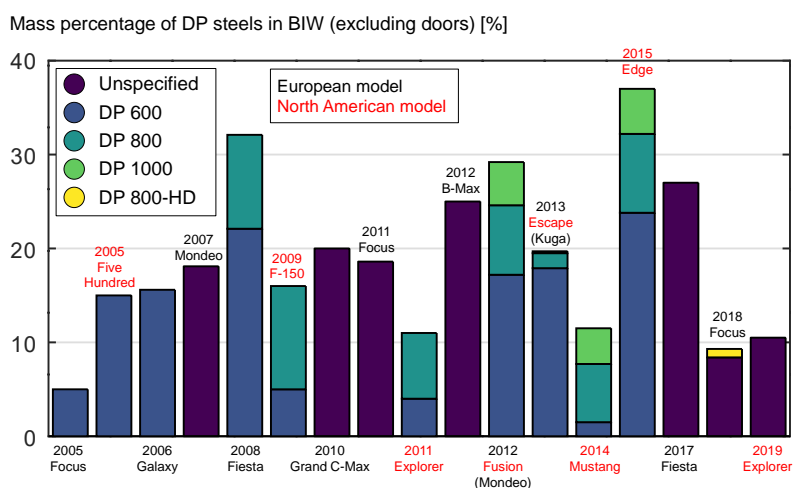

Fig. 2 Dual phase steel usage in several European and North American Ford Models

Although AHSS have higher formability (could be measured by total elongation, $\mathrm{FLC}_{0}$, nvalue at various intervals) compared to conventional HSS, as the strength level is increased, several forming challenges are still faced. These are [5]:

- Early fractures, especially due to local edge cracks

- Hard to control spring back

- Faster tool wear (shorter tool lives)

- Requirement of larger press capacities (both in force and energy)

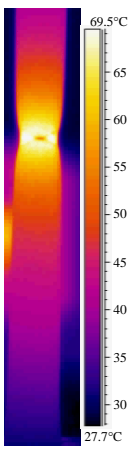

Slow

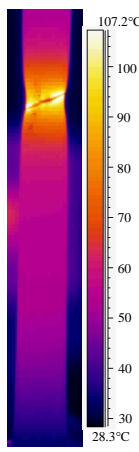

Fast

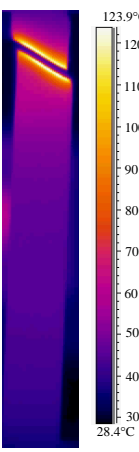

Slow

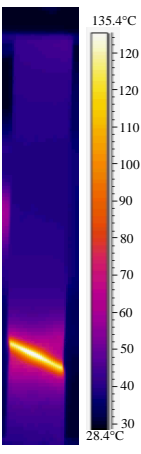

Fast

DC04 (Deep Drawing Steel) HCT980X (DP 1000)

Fig. 3 Thermal images of tensile specimens just before fracture [7]

During press forming, significant amount of force (in the order of several hundreds of tons) is applied along the forming stroke (in the order of several hundreds of mm's). As a rule of thumb, $90 \%$ of the forming energy (integral of the force-stroke curve) is considered to be converted into heat [6]. Fig. 3 shows thermal camera images, captured at 50 frames per second. Two different materials were studied, a mild steel and an AHSS, DP1000. Two findings from this study could be: higher local maximum temperatures can be observed (1) when higher strength steels are deformed, and (2) when deformation is done faster. These thermal images show heat generation due to plastic deformation only [7].

In press forming, there would be heat generation due to plastic deformation and also, due to the friction between the blank and the tools. Local high temperatures would be observed with: (a) deeper draws, (b) higher strength materials and (c) high press speeds $[8,9]$. When the speed of forming is increased - i.e., higher stroked per minute (SPM's), which are 
favored in mass production, due to increased production volume - there would be less time for heat to dissipate and local temperatures may be even higher. Heat generation (or increased die temperatures) may affect the robustness of mass production of stamped components. A study at Volvo showed that in deep drawing of mild steels, even at 8 SPM, tool temperatures may increase by $10^{\circ} \mathrm{C}$, causing splits in the drawn panel. The problem was initially solved by reducing the blankholder force after several strokes. Later, Volvo switched to a lower-friction coating (from GI to Zinc-Magnesium) [10]. Another solution, rather costly one, for high volume parts is to use an in-die cooling system, similar to hot stamping dies. Fig. 4, shows BMW's deep drawing tools for mild steels and AHSS. Cooling system was only used in high-volume AHSS applications [9].

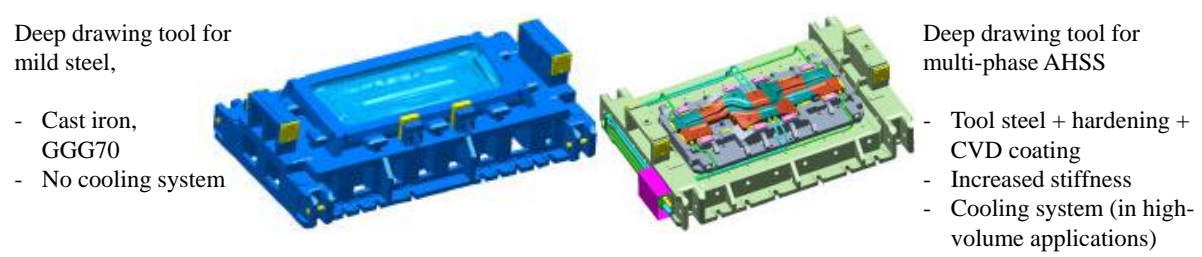

(a)

(b)

Fig. 4 Deep drawing tool design at BMW: (a) for mild steels, (b) for multi-phase AHSS (e.g., TRIP700) [9].

In this study, heat generation during deep drawing of DP800 is simulated, and the results are compared with the experiments in the literature.

\section{Material Model}

DP800 (sometimes also called as DP780) is selected, as this grade can be used in most applications in a car body (as shown in Fig. 1). There are several standards in Europe which defines chemical and mechanical properties of DP800. Table 1 summarizes the mechanical properties of DP800 equivalents in the European Norm EN 10338 [11], German Association of the Automotive Industry's VDA239-100 [12] and Ford's internal standard WSS-M1A368 [13]. It is important to note that these steels also have bake-hardening effect.

Table 1. DP800 material in different standards $[11,12,13]$.

\begin{tabular}{cccc}
\hline Standard & EN10338 & VDA239-100 & WSS-M1A368 \\
\hline Naming - Primary & HCT780X & CR440Y780T-DP & CRDP800 \\
(Secondary) & $(1.0943)$ & $(-)$ & (A14) \\
\hline Proof strength $\left(\mathrm{R}_{\mathrm{p} 0.2}\right.$ ) [MPa] & $440-550$ & $440-550$ & $420-550$ \\
Tensile strength $\left(\mathrm{R}_{\mathrm{m}}\right.$ ) [MPa] & $\geq 780$ & $780-900$ & $780-900$ \\
Total elongation $\left(\mathrm{A}_{80}\right)[\%]$ & $\geq 14$ & $\geq 14$ & $\geq 14$ \\
$\mathrm{n}_{4-6}[-]$ & - & $\geq 0.15$ & $\geq 0.15$ \\
$\mathrm{n}_{10-20 / \mathrm{Ag}}[-]$ & $\geq 0.11$ & $\geq 0.11$ & $\geq 0.11$ \\
$\mathrm{BH}_{2}[\mathrm{MPa}]$ & $\geq 30$ & $\geq 30$ & $\geq 30$ \\
\hline
\end{tabular}

To simulate a metal forming process, three key material data are required. These are:

1) Flow curve(s): true plastic strain-true stress curves for all conditions (i.e., if needed, at various temperature levels and strain rates).

2) Yield locus is used to calculate stress and strain tensors in multi-axial stress conditions. 
3) Failure criterion: typically forming limit curve (FLC) is used, it is also possible to use thinning limit curve (TLC) or triaxial failure curve (TFC).

In this study, commercially available metal forming simulation software, AutoForm ${ }^{\circledR}$ R8 with Thermo Plug-In was used for simulations. Material data was taken from AutoForm material library using Tata Steel's DP800 GI (Galvanized) Thermo model. There were 24 flow curves (4 temperature levels and a total of 6 strain rates), some of them are plotted in Fig. 5 [14].
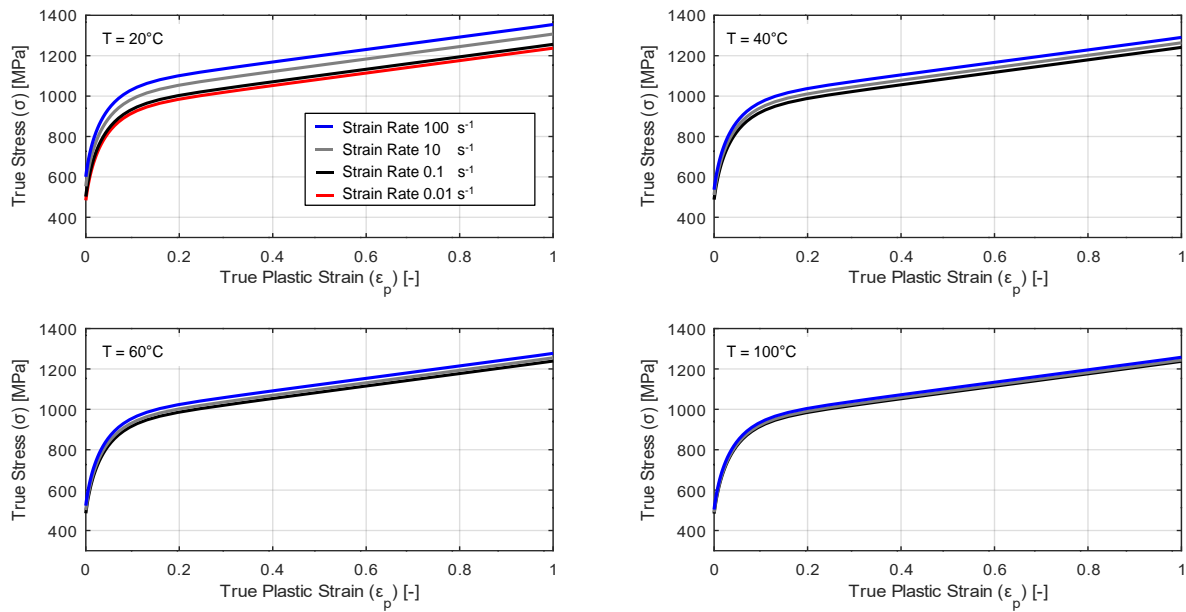

Fig. 5 Flow curves of all temperatures and some of the strain rates (re-created after [14])

In this study, Vegter 2006 (also known as Corus-Vegter or Vegter-Full) yield locus is used. To generate the yield locus, a total of 4 different experiments and 13 tests are required: (1) uniaxial tensile tests in 3 directions, with r-value determination, (2) shear test in 3 directions, (3) plane-strain test in 3 directions and (4) a biaxial test (preferably hydraulic bulge test) [15]. In this study, isotropic hardening is used [14].

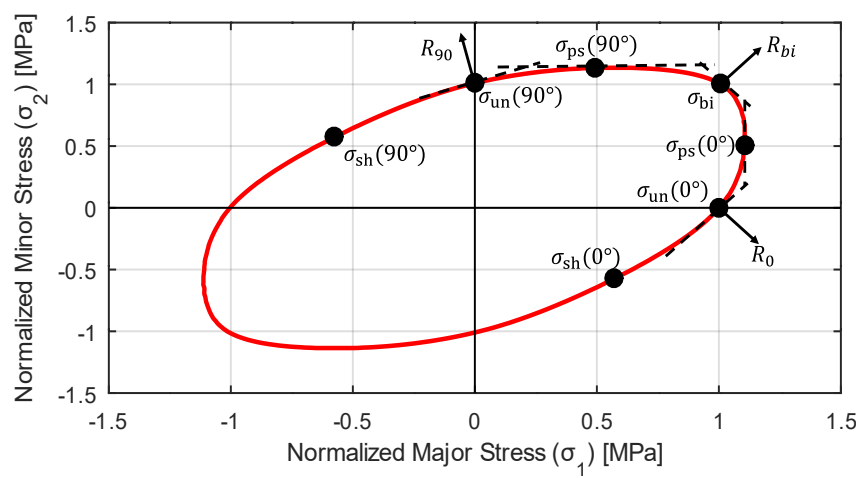

Fig. 6 Yield locus of DP800, using Vegter 2006 yield criterion (re-created after [14, 16]) 
Table 2. Parameters of Vegter yield locus at $20^{\circ} \mathrm{C}$ temperature and $0.01 \mathrm{~s}^{-1}$ strain rate [14]

\begin{tabular}{ccccc}
\hline Parameter & \multicolumn{3}{c}{ Angle to rolling direction } & \\
\cline { 2 - 4 } & $0^{\circ}$ & $45^{\circ}$ & $90^{\circ}$ & \\
\hline Uniaxial Yield Strength $\left(\sigma_{\mathrm{un}}\right)[\mathrm{MPa}]$ & 484 & 482 & 490 & 487 \\
Normalized $\sigma_{\mathrm{un}}[-]$ & 1 & 0.996 & 1.013 & 1.007 \\
r-values & 0.750 & 0.850 & 0.875 & 0.857 \\
Shear Strength $\left(\sigma_{\mathrm{sh}}\right)[\mathrm{MPa}]$ & 279 & 276 & 276 & - \\
Normalized $\sigma_{\mathrm{sh}}[-]$ & 0.577 & 0.570 & 0.570 & - \\
Plane-strain Strength $\left[\sigma_{\mathrm{ps}}\right)[\mathrm{MPa}]$ & 536 & 541 & 552 & - \\
Normalized $\sigma_{\mathrm{ps}}[\mathrm{MPa}]$ & 1.107 & 1.117 & 1.140 & - \\
Plane-strain Minor Stress $\left(\sigma_{\mathrm{ps} 2}\right)[\mathrm{MPa}]$ & 247 & 250 & 238 & - \\
Normalized $\left(\sigma_{\mathrm{ps} 2}\right)[\mathrm{MPa}]$ & 0.511 & 0.516 & 0.492 & - \\
\hline
\end{tabular}

Lastly for the Forming Limit Curve, Abspoel 2012 model is used - commonly referred to as Tata Steel model. In this model, r-values and total elongation $\left(\mathrm{A}_{80}\right)$ values for all 3 directions $\left(0^{\circ}, 45^{\circ}\right.$ and $90^{\circ}$ to rolling direction) and thickness of the blank are required. The output will be similar to Marciniak FLC (i.e., FLC $_{0}$ coinciding with the y-axis) with only 4 data-points, as clearly indicated in Fig. 7 [17]. FLC is given for only $20^{\circ} \mathrm{C}$. When the thickness is different than that of the FLC, Keeler approximation is used to calculate the new FLC.

In automotive industry, "failure criterion" is used when designing a die with simulation. For a given element, assume the maximum minor-major strain distribution during forming would be point $A$ in Fig. 7. The failure criterion is the linear distance from origin to point $A$ divided to the linear distance to the FLC. In Fig. 7, point A's failure criterion is approximately 0.5 . In theory if failure criterion is equal to or over 1.0, the part would split. During die design process, failure criterion is typically kept around 0.7-0.8 to have a robust production.

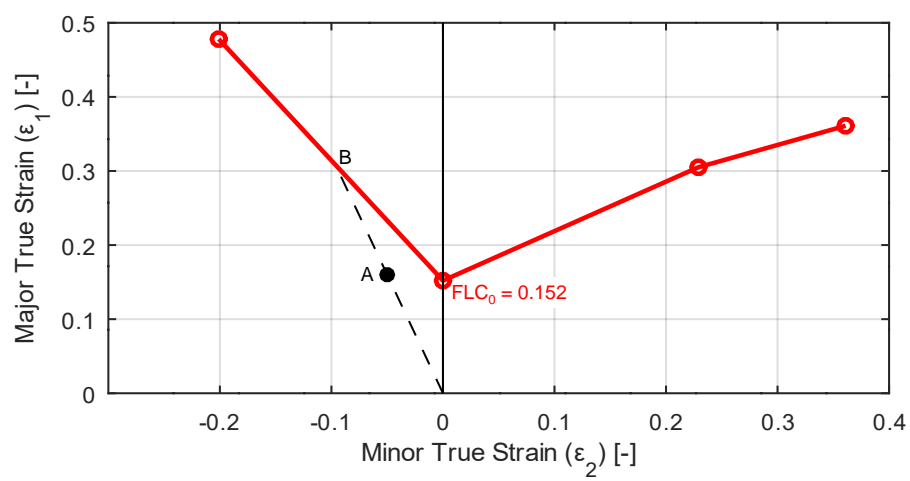

Fig. 7 Forming Limit Curve of $1.6 \mathrm{~mm}$ thick DP800 [14].

\section{Simulations}

In this study, a new deep drawing tool for DP800 has been developed, considering the heat generation effects. The thermomechanical finite element simulations were first validated with experiments in the literature. 


\subsection{Validation of Thermomechanical Model}

To validate the predictions of the thermomechanical model, Pereira and Rolfe's experimental study [18] was replicated. The dimensions of the tools are given in Figure 10. Pereire and Rolfe studied a number of different sheet steels, in this study only $2.0 \mathrm{~mm}$ DP800 is replicated. Tools were considered to be uniformly $20^{\circ} \mathrm{C}$ before the forming process. Tools were modeled with 3D heat conduction, and a $100 \mathrm{~mm}$ tool height was added. Thus, the tools may heat up after stamping process. Simulation parameters are summarized in Table 3. In these simulations, mechanical press is simulated with a motion curve, developed by one of the co-authors.
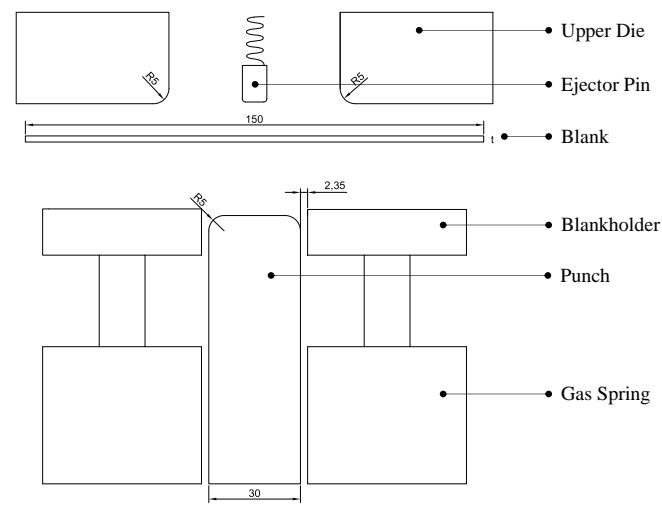

Fig. 10 Schematic view of the tools (re-created after [18])

Table 3. Simulation parameters

\begin{tabular}{ccc} 
Friction coefficient [-] & \multicolumn{2}{c}{0.15} \\
Blankholder force [kN] & \multicolumn{2}{c}{27.2} \\
Draw depth [mm] & \multicolumn{2}{c}{40} \\
Mechanical press stroke length [mm] & \multicolumn{2}{c}{203.2} \\
Stroke rate [SPM] & \multicolumn{2}{c}{1} \\
Thermal properties & Tools & Sheet \\
Initial Temperature $\left[{ }^{\circ} \mathrm{C}\right]$ & 20 & 20 \\
Heat Conductivity $\left[\mathrm{W} / \mathrm{m}^{\circ} \mathrm{K}\right]$ & 22 & 52 \\
Volumetric Heat Capacity $\left[\mathrm{m} / \mathrm{mm}^{3 \circ} \mathrm{K}\right]$ & 3.588 & 3.564
\end{tabular}




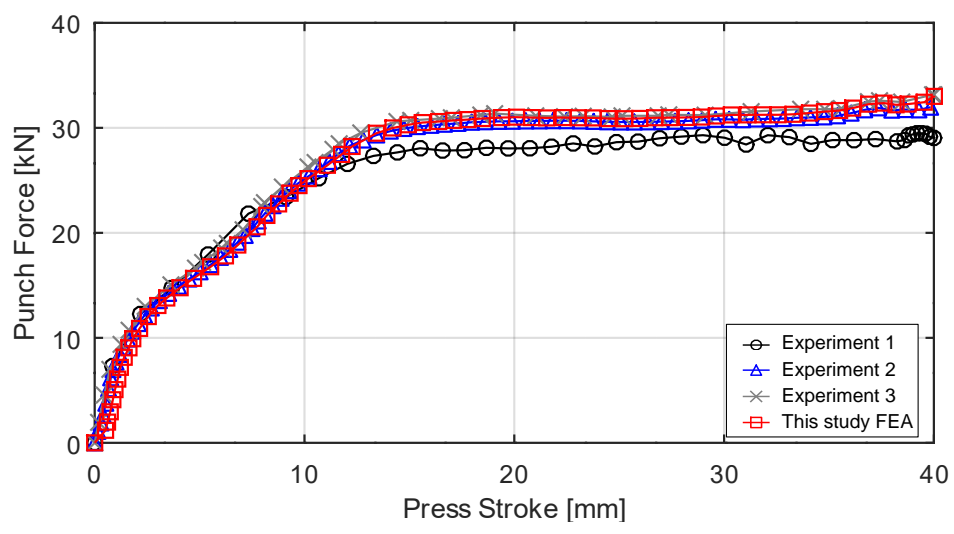

Fig. 8 Punch force vs. press stroke, experiments from [18].

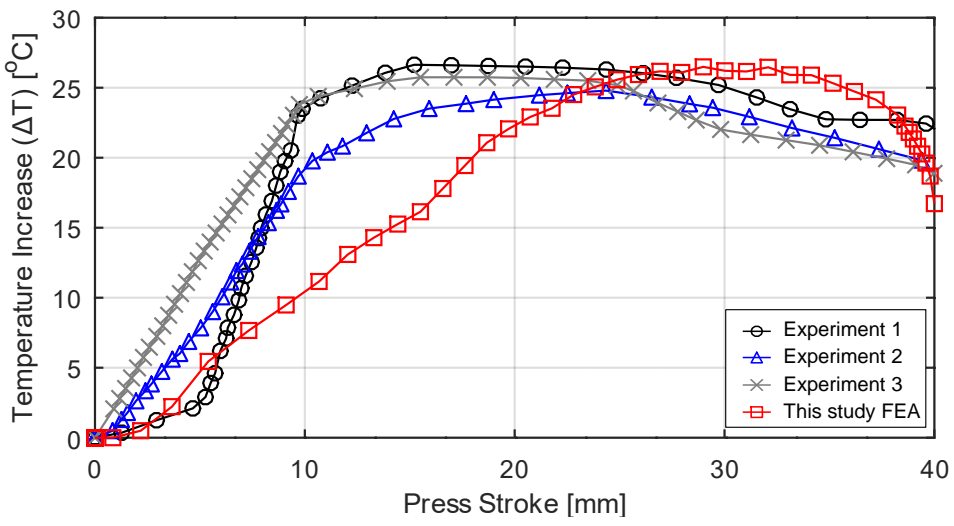

Fig. 9 Temperature increase in the blank, experiments from [18].

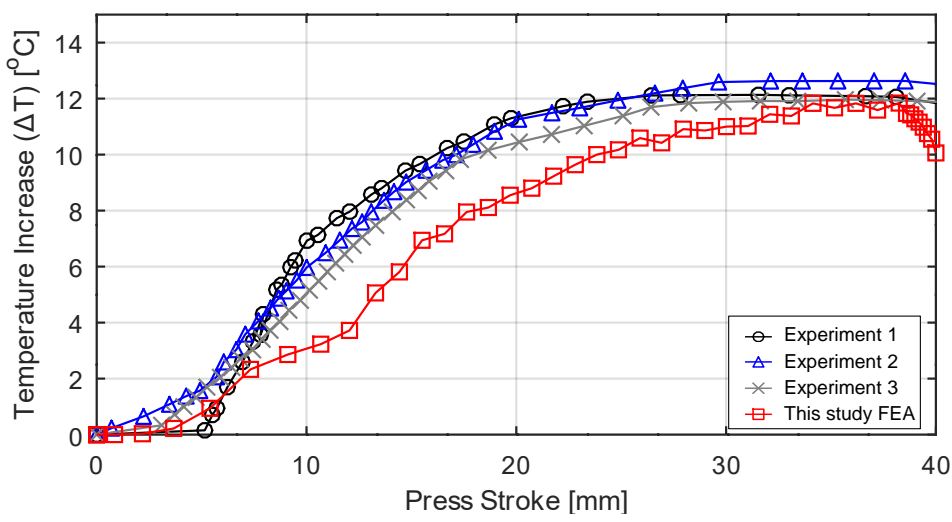

Fig. 10 Temperature increase of the tools (measured below upper die surface). 
Pereira and Rolfe made all the experiments and measurements with five repetitions. In this study, we digitized three of them to compare our simulation results. By this method, the figures would be easier to read. The three data sets were selected as the highest values, lowest values and the average. The first comparison was done in punch force vs. stroke. As seen in Fig. 8, the curves were very close. The discrepancy at the bottom of the stroke may be due to the gas springs' compression. As the paper did not share the details of the gas springs, but assumed an average force of $27.2 \mathrm{kN}$, the effect of compression had to be neglected. The second comparison was done on the temperature of the blank. As seen Fig. 9 , the peak temperature calculated in the simulation overestimated the experimental peak temperature by only $0.15-1.84^{\circ} \mathrm{C}$. On the other hand, tool temperatures are slightly underestimated by $0.13-0.79^{\circ} \mathrm{C}$. These can be explained by heat transfer coefficient between the blank and the tool, constant friction coefficient, variation of material properties between the material card and the experiments. Still, the results show the thermomechanical model has good correlation with the experiments.

\subsection{Developing the DP800 Draw Die Model}

In this study, the effect of tool temperature on deep drawability of DP800 is studied. In order to measure the effect of tool temperature, the cup draw test die set (i.e., only a draw ring, not a full die cavity) defined by Ju et al. [19] was slightly modified. Ju et al. used a punch with vertical wall. In most automotive applications, to facilitate drawing and ejecting the part, the punch typically has a positive wall angle. Although it may vary from part to part, a wall angle of $7^{\circ}$ is quite common. The die set, shown in Figure 14, is designed for parts up to $170 \mathrm{~mm}$ depth.

Lubrication (or in simulation terms, friction) affects the deep drawability. In most studies, various oil or water-based lubricants are applied. In automotive industry, for environmental concerns, "dry press shops" are favored. In a so-called "dry press shop", the blanks are formed with the mill oil with no additional lubricant [20]. Mill oil is the oil film on the coil to avoid corrosion during shipping, typically between $1.0-2.0 \mathrm{~g} / \mathrm{m}^{2}$.

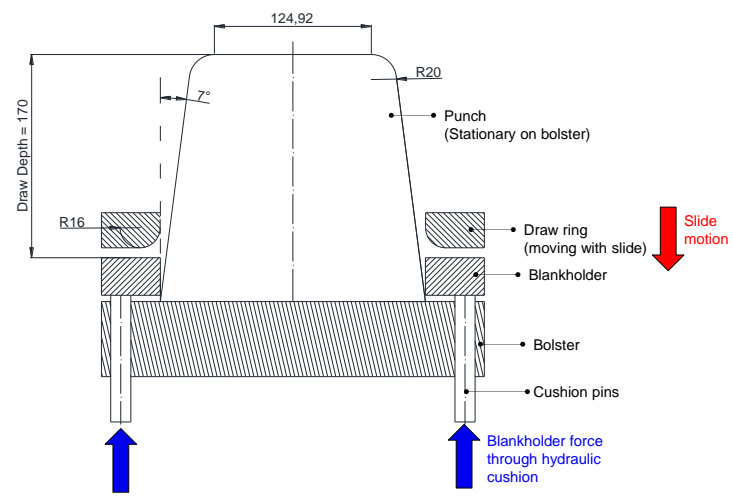

Fig. 14 Cup draw die set-up.

In this study, the simulations were run with only mill oil. The friction coefficient was not selected as a constant value throughout the part, but instead TriboForm Plug-in was used. $1.0 \mathrm{~g} / \mathrm{m}^{2}$ oil was selected and the Dual Phase GI friction model was imported from TriboForm library.

In industrial production, a link motion press is used for deep drawing. The press has frequency inverter speed control, adjustable from 8 to 22 strokes per minute (SPM). The 
real stroke-time curves of the deep draw press at Otosan are shown with red color in Fig. 11. To study the effect of press speed, a mechanical press without link motion, but the same stroke length and SPM were also modeled. Black curves in Fig. 11 show this fictious mechanical press stroke-time profiles.

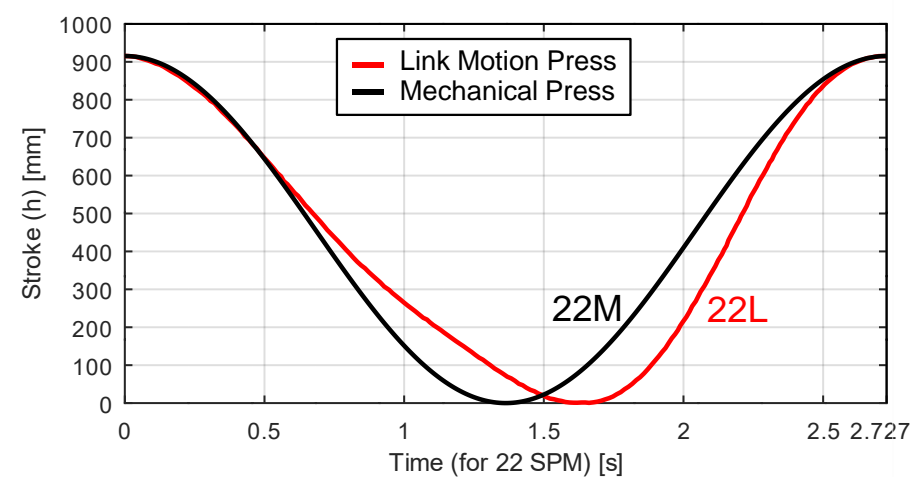

(a)

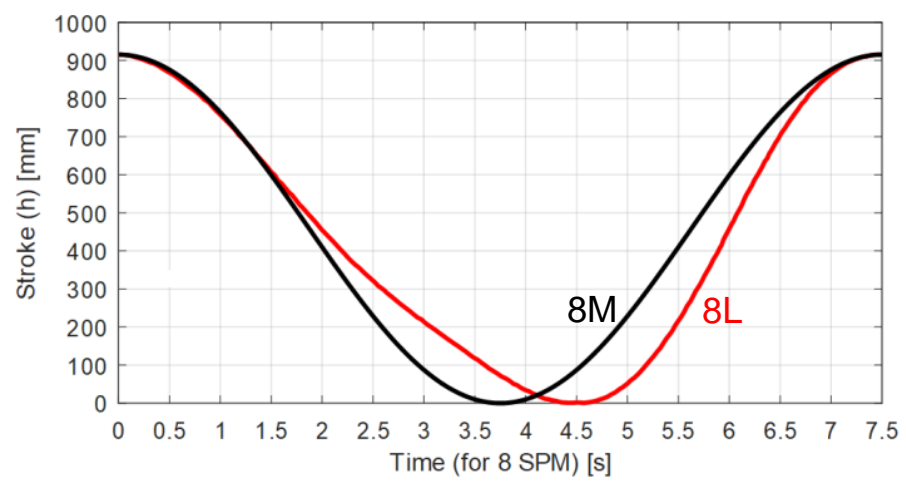

(b)

Fig. 11 Press stroke-time curves for link-motion and mechanical press with $916 \mathrm{~mm}$ stroke: (a) at maximum speed of the line (22 SPM) and (b) at minimum speed of the line (8 SPM).

Between 4 different models, several differences would be simulated:

1) Due to decreased press speed, at $8 \mathrm{SPM}$, flow stress would be slightly lower, due to lower strain rate;

2) Since TriboForm plug-in is used, as the velocity is decreased, friction coefficient will increase;

3) As Thermo plug-in is used, there would be heat generation in the blank (due to plastic deformation) and die-blank interface (due to friction). At high speeds, there would be less time to dissipate the heat. Higher local temperatures may occur, softening the steel; but increasing the friction. 
Due to all these interacting effects of press speed (SPM and type), it was found that if the blankholder force would be kept constant between 4 different models, significant changes in formability would occur. Thus, to have comparable results, blankholder force was changed to keep the "failure criterion" (FC) as close as possible after the first hit. Table 4 shows the parameters and the FC values after first hit. Incoming blanks at each hit are assumed to be $20^{\circ} \mathrm{C}$. The tools were uniformly at $20^{\circ} \mathrm{C}$ before the first hit, but are allowed to accumulate heat after each hit. Tools lose some of the heat to the environment through convection.

Table 4. Simulation parameters and failure criteria after first hit.

\begin{tabular}{ccccc}
\hline Short name & $\begin{array}{c}\text { Press Speed } \\
\text { (SPM) }\end{array}$ & Press Type & $\begin{array}{c}\text { Blankholder } \\
\text { Force }(\mathrm{kN})\end{array}$ & $\begin{array}{c}\text { FC after first } \\
\text { hit }\end{array}$ \\
\hline $8 \mathrm{M}$ & 8 & Mech. & 78 & 0.677 \\
$8 \mathrm{~L}$ & 8 & Link & 77 & 0.675 \\
22M & 22 & Mech. & 80 & 0.676 \\
22L & 22 & Link & 87 & 0.679 \\
\hline
\end{tabular}

\section{Results}

In the automotive industry, process is designed such that the FC value is kept under 0.7 0.8 - depending on the part complexity. In this study, the FC values after the first hit were kept very close to 0.7 intentionally. Then, more cycles are run until the $\mathrm{FC}$ value surpasses 1.0. In this case, the part is considered to have a split (failure). Figures 12 through 15 summarizes the change of FC values and tool temperature. Here, the local maximum temperature on any tool surface (punch, die or blankholder) is shown.

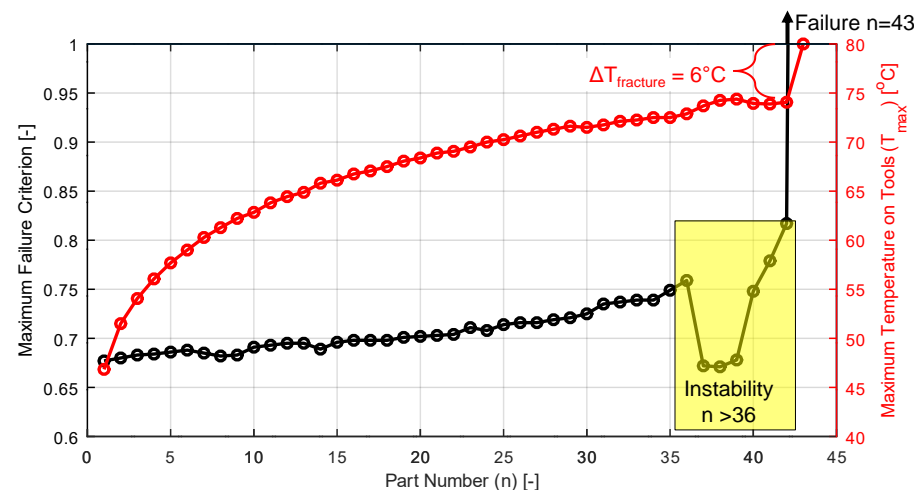

Fig. 12 Condition $8 \mathrm{M}$ : failure at $43^{\text {rd }}$ part with over $74^{\circ} \mathrm{C}$ maximum tool temperature 


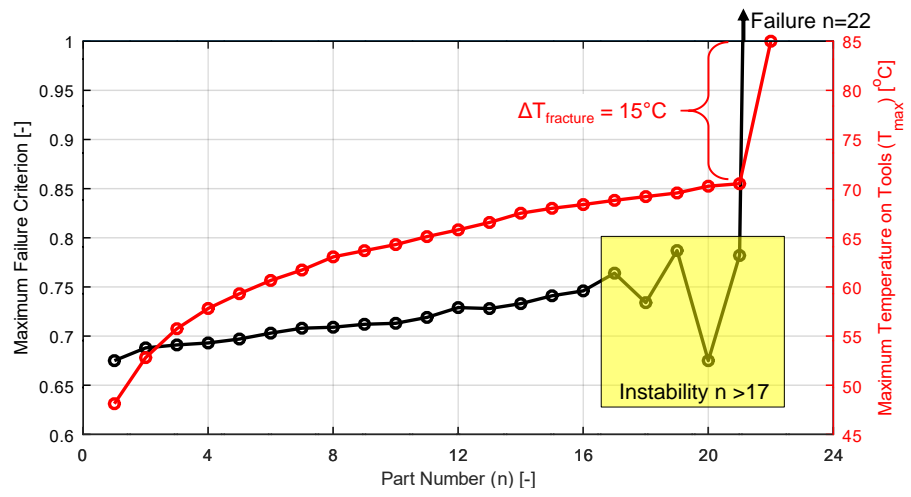

Fig. 13 Condition $8 \mathrm{~L}$ : failure at $22^{\text {nd }}$ part with over $70^{\circ} \mathrm{C}$ maximum tool temperature

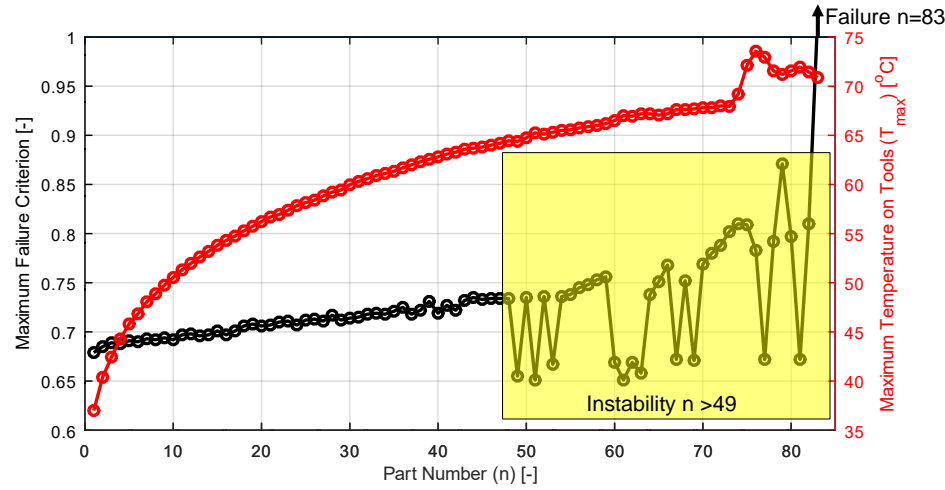

Fig. 14 Condition $22 \mathrm{M}$ : failure at $83^{\text {rd }}$ part with over $71^{\circ} \mathrm{C}$ maximum tool temperature.

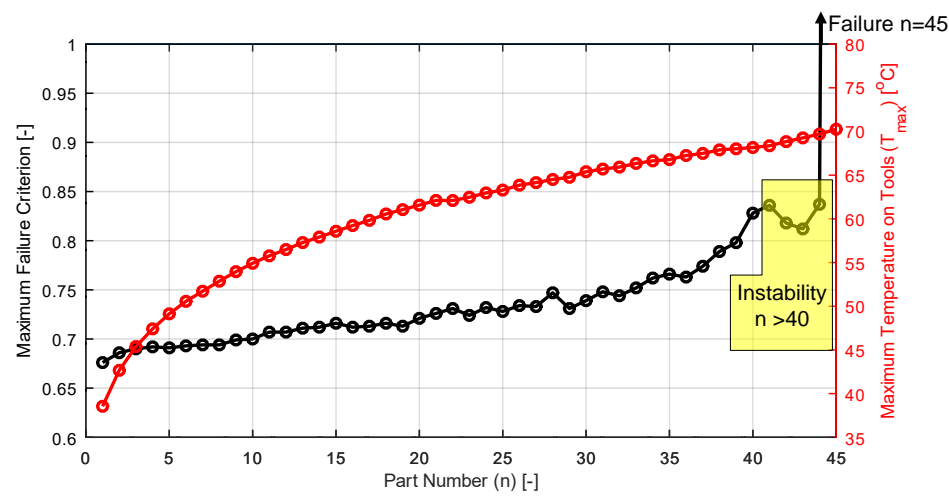

Fig. 15 Condition $22 \mathrm{~L}$ : failure at $45^{\text {th }}$ part with over $70^{\circ} \mathrm{C}$ maximum tool temperature.

In most stamping operations, the first hit has a much lower $\mathrm{FC}$ value, and it takes much longer to have a failure due to heating (over 300-500 hits [10, 21]). In this particular design, use of strong steel (DP800) with very deep draw $(170 \mathrm{~mm})$ may have accelerated the failure due to tool temperature. This was intentionally done to: (1) reduce the simulation time, and (2) keep the failure below 100 cycles, which was the limitation of the software. 
In all conditions, a few hits before the failure, FC values are lowered. This is marked as "instability". This could be due to a glitch in the mathematical model and requires further investigation.

Overall, once the tool temperatures surpass $70^{\circ} \mathrm{C}$, failure is observed. According to Waanders et al., friction coefficient may increase by $40 \%$ at temperatures over $60^{\circ} \mathrm{C}$ [21].

Contrary to expectations, link motion presses seemed to be disadvantageous in this study. This can be explained by the increased friction coefficient due to reduced slide velocity and reduced time to dissipate the heat energy in link motion presses. In reality, the lower shock at force build-up improves the lubrication condition. Another problem was the idle times: durations of final part (hot) and incoming blank (cold) sitting on the tools. Mathematical model could be improved by measuring real idle times on a press line.

Figure 16 shows the local maximum temperature of the blanks after each hit - excluding the fractured part. As expected, blank temperatures are higher at 22 SPM. At low SPM's, the blank drawn in a link motion press has lower temperature. Similar to FC-values, before fracture, the maximum temperatures seem to reduce in the last few hits. It is very critical to note that, the material card had flow curves only until $100^{\circ} \mathrm{C}$ (see Fig. 5). Over this temperature, extrapolation was used.

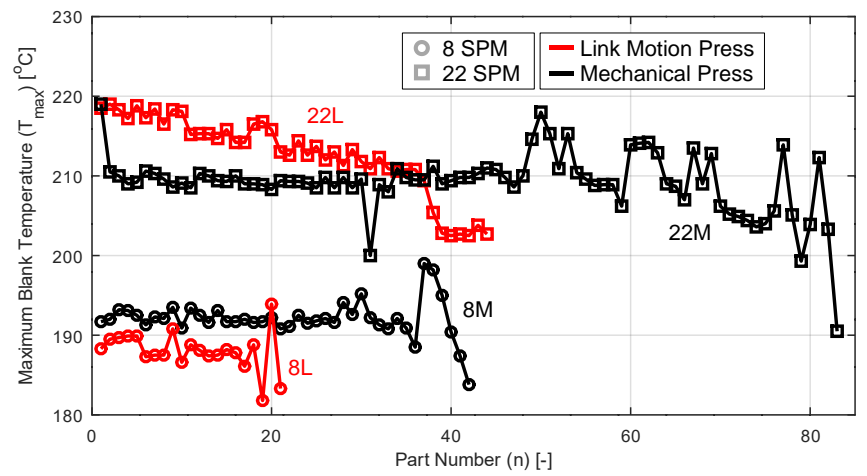

Figure 16 Maximum blank temperature in all 4 conditions.

\section{Conclusions and Future Work}

A mathematical model for heat generation has been developed and validated with experiments from literature. After the first hit, the temperature predictions were within $\pm 2^{\circ} \mathrm{C}$.

Once this model is validated, a multi-cycle model is generated. The die design and material selection were done to speed up the heat generation, such that, after only 22 to 83 hits failures were observed.

Several improvements could be done in the mathematical model, such as:

1) Temperature dependent FLC may be required to further improve FC-value predictions,

2) Higher temperature flow curves could reduce the error due to extrapolation,

3) Correction of idle times on the tools may change the tool temperatures,

4) Friction model requires further investigation. 
After the proposed work done, it is possible to find the best possible process window to improve productivity (higher SPM) and reduce costs (due to scrapping of failed parts). A draw die with built-in cooling channels is planned for further experimental studies.

\section{Acknowledgments}

Authors would like to thank Dr. Alper Güner, AutoForm Engineering Deutschland GmbH, Mr. Nihat Kurtuluş from Grup Otomasyon, and Mr. Metehan Karaköse for their valuable input in this article.

\section{References}

[1] J. R. Fekete and J. N. Hall, "1 - Design of auto body: Materials perspective," in Automotive Steels, R. Rana and S. B. Singh, Eds., Woodhead Publishing, 2017, pp. 1-18. https://doi.org/10.1016/B978-0-08-100638-2.00001-8

[2] Posco, "Automotive Steel Data Book," 2016.

[3] T. B. Hilditch, T. de Souza and P. D. Hodgson, "2 - Properties and automotive applications of advanced high-strength steels (AHSS)," in Welding and Joining of Advanced High Strength Steels (AHSS), M. Shome and M. Tumuluru, Eds., Woodhead Publishing, 2015, pp. 9-28. https://doi.org/10.1016/B978-0-85709-436-0.00002-3

[4] F. Özkan and A. Bach, "Future trends and challenges in using AHSS in body structure," Presented at PHS Suppliers Forum, September 19, Troy, MI, 2019.

[5] E. Billur and T. Altan, "Challenges in forming advanced high strength steels," Proceedings of New Developments in Sheet Metal Forming, p. 285-304, 2010.

[6] A. Fallahiarezoodar, R. Peker and T. Altan, "Temperature Increase in Forming of Advanced High-Strength Steels Effect of Ram Speed Using a Servodrive Press," Journal of Manufacturing Science and Engineering, vol. 138, 72016. https://doi.org/10.1115/1.4033996

[7] E. Billur, "Heating helps cutting - Adiabatic cutting of high strength sheets," Metalforming Magazine, December 2020 Issue, p. 12-13, 2020.

[8] E. Ceron and N. Bay, "Testing and prediction of limits of lubrication in sheet metal forming," in iddrg 2012 incorporating SMF 2012: Lightweighting: Possibilities \& Challenges, 2012.

[9] M. Pfestorf, "Manufacturing of high strength steel and aluminum for a mixed material body in white," in Advanced Materials Research, 2005. https://doi.org/10.4028/087849-972-5.109

[10] N. Kurtulus, "New Developments in Sheet Metal Forming Simulations," in Proceedings of the 2nd Metal Forming Technology Day (meftech2019), Istanbul, TR, 2019.

[11] EN 10338, "Hot and cold rolled non-coated flat products of multi-phase steels for cold forming - Technical delivery conditions," European Standard, 2015.

[12] Verband Der Automotbilindustrie E.V. (VDA), "Sheet Steel for Cold Forming," Material Specifications, 2016.

[13] Ford Global Technologies LLC, "WSS-M1-A368 - Engineering Material Specification," Company Standard, 2017.

[14] Tata Steel, «CR_DP800-GI_Vegter+thermo_1.2-1.6.mtb,» AutoForm Material Card, 2019.

[15] H. Vegter and A. H. van den Boogaard, "A plane stress yield function for anisotropic sheet material by interpolation of biaxial stress states," International Journal of Plasticity, vol. 22, pp. 557-580, 2006. https://doi.org/10.1016/j.ijplas.2005.04.009

[16] H. Vegter, C. ten Horn and M. Abspoel, "The corus-vegter lite material model: simplifying advanced material modelling," International Journal of Material Forming, vol. 2, p. 511, 1512 2009. https://doi.org/10.1007/s12289-009-0640-4 
[17] M. Abspoel, M. E. Scholting and J. M. M. Droog, "A new method for predicting Forming Limit Curves from mechanical properties," Journal of Materials Processing Technology, vol. 213, pp. 759-769, 2013. https://doi.org/10.1016/i.jmatprotec.2012.11.022

[18] M. P. Pereira and B. F. Rolfe, "Temperature conditions during 'cold' sheet metal stamping," Journal of Materials Processing Technology, vol. 214, pp. 1749-1758, 2014. https://doi.org/10.1016/i.jmatprotec.2014.03.020

[19] L. Ju, T. Mao, J. Malpica and T. Altan, "Evaluation of Lubricants for Stamping of Al 5182 O Aluminum Sheet Using Cup Drawing Test," Journal of Manufacturing Science and Engineering, vol. 137, 9 2015. https://doi.org/10.1115/1.4030750

[20] N. Asnafi, "Tooling and Technologies for Processing of Ultra High Strength Sheet Steels," Presented at Tool and Technologies for Processing Ultra High Strengh Materials, TTP2011, Graz, Austria, 2011.

[21] D. Waanders, J. H. Marangalou, M. Kott, S. Gastebois and J. Hol, "Temperature Dependent Friction Modelling: The Influence of Temperature on Product Quality," Procedia Manufacturing, vol. 47, pp. 535-540, 2020. https://doi.org/10.1016/j.promfg.2020.04.159 